\title{
Chemical Profile and Hepatoprotective Activity of Ethyl Acetate Extracts of Euphorbia paralias and Euphorbia geniculata (Euphorbiaceae) from Egypt
}

\author{
Afaf E. Abdel Ghani', Sayed A El-Toumy², Wagdi l. A. El-Dougdoug'2 , Ahmed M. Mansour², Wafaa H. B. Hassan², \\ Hanaa M. Hassan ${ }^{3, *}$
}

Afaf E. Abdel Ghani', Sayed

A El-Toumy ${ }^{2}$, Wagdi I. A.

El-Dougdoug'2, Ahmed M.

Mansour ${ }^{2}$, Wafaa H. B. Hassan², Hanaa M. Hassan ${ }^{3, *}$

'Department of Pharmacognosy, Faculty of Pharmacy, Zagazig University, 44519

Zagazig, Egypt.

${ }^{2}$ Chemistry of Tannins Department, National Research Centre, 12622 Dokki, Cairo,

${ }^{3}$ Department of Organic Chemistry, Faculty of Science, Banha University, 13518 Banha, Egypt.

${ }^{4}$ Department of Pharmacology and

Toxicology Faculty of Pharmacy, El-Alazhar University Cairo, Egypt.

${ }^{5}$ Department of Pharmacognosy Faculty

of Pharmacy, Zagazig University," Zagazig,

Egypt.

${ }^{6}$ Pharmacy Department Banha Educational

Hospital, 13518 Banha, Egypt.

\section{Correspondence}

Hanaa M Hassan

Pharmacy Department Banha Educational

Hospital, 13518, Banha, Egypt.

E-mail: hanaazain111@yahoo.com

History

- Submission Date: 11-02-2020;

- Review completed: 03-03-2020

- Accepted Date: 25-03-2020

DOI : 10.5530/pj.2020.12.109

Article Available online

http://www.phcogj.com/v12/i4

Copyright

(C) 2020 Phcogj.Com. This is an openaccess article distributed under the term of the Creative Commons Attribution 4.0 International license.

\begin{abstract}
Background: Plants belonging to the genus Euphorbia were used traditionally to treat several health disorders and diseases. Objective: the aim of this study is evaluation of secondary metabolites and hepatoprotective activity of the ethyl acetate fractions of the aerial parts of Euphorbia paralias (Ep) and Euphorbia geniculata (Eg). Materials and Methods: UPLC-ESI-MS/ MS technique was used for identification of the secondary metabolites. The hepatoprotective potential of the two plants was evaluated for the first time in male rats with thioacetamide induced liver injury. Results: A total of 32 secondary metabolites were identified in the ethyl acetate fractions of the aerial parts of both species. Ellagitannins such as tetragalloyl hexoside, ellagic acid, gallic acid, and flavonoids such as kaempferol-3-O- $\beta-\left(6^{\prime \prime}\right.$-galloyl-Oglucopyranoside), quercetin glycosides (glucoside and arabinoside) were found to be the major components in $E p$ whereas flavonoid glycosides including quercetin rutinoside, quercetin glycosides (glucoside, arabinoside and rhamnoside) and kaempeferol glycoside derivatives were highly abundant in Eg. Administration of thioacetamide resulted in marked elevation in liver enzymes, elevation of lipid profile and alteration in oxidative stress parameters. While pretreatment of rats with Ep and Eg ethyl acetate fractions significantly attenuated the hepatic toxicity through reduction of liver biomarkers, improving the redox status of the tissue and so brought down the serum biochemical parameters and lipid profile nearly toward the normal levels. Conclusion: The studied fractions show hepatoprotective potential with promising value as hepatoprotective drugs of natural origin in comparison with silymarin as the standard hepatoprotective drug.
\end{abstract}

Key words: Euphorbia, UPLC-ESI-MS/MS, Polyphenolics, Hepatoprotective.

\section{INTRODUCTION}

Plants have used as an essential source of drugs and remedies on treatment of diseases and health disorders since ancient times ${ }^{1}$. Flavonoids and phenolic compounds containing plants which are common among medicinal plants were reported for its various health benefits and applications. They have a wide spectrum of pharmacological activities including antiinflammatory, antioxidant, hepatoprotective, anticancer and antimicrobial activities. They also decrease the risk of cardiovascular diseases, enhance regeneration of the liver and increase life expectancy ${ }^{2,3}$. As liver damage can be life threatening and its damage is caused by several factors such as alcohol, viruses, organic chemicals, metabolic and genetic abnormalities. Liver transplantation was improved survival rate of patients in some cases only and is limited to a small number of patients due to non-availability of suitable donors. And so, finding new drugs that are able to enhance liver regeneration and prevent liver failure is a very important need. Natural products as plant extracts exhibiting antioxidant and hepatoprotective activities can be useful in these needs ${ }^{2}$. The aim of the current study was to identify the polyphenolics and flavonoids in the ethyl acetate (EA) fractions of the aerial parts of $E p$ and $E g$ using UPLC-ESI-MS/MS and to investigate the possible hepatoprotective activities of the studied fractions.

\section{MATERIALS AND METHODS}

\section{Plant material and extraction}

Aerial parts of E. paralias L. and E. geniculata Ortega were collected in the flowering stage on May and August 2015, respectively. E. paralias was collected from the North beach of Alexandria, Egypt. While E. geniculata was collected from roadsides in the vicinity of Banha, Qalubya, Egypt. The identification was kindly verified by Dr. Ahmed Abd El-Razik Lecturer of Plant Taxonomy, Department of Botany, Faculty of Science, Banha University, Egypt. The vouchers specimens (no. S303 and S304) were deposited in National Research Centre, Dokki, Cairo, Egypt. The air-dried powdered plant materials $E p$ and $E g$ (500 g of each plant) were extracted by cold maceration with $70 \%$ methanol until complete exhaustion. The methanolic extracts were evaporated under reduced pressure at $45^{\circ} \mathrm{C}$. The greenish brown viscous residues (105.0 and 100.5 gm respectively) were separately dissolved in $\mathrm{MeOH}-\mathrm{H}_{2} \mathrm{O}$ mixture 
$(500 \mathrm{ml}, 1: 9 \mathrm{v} / \mathrm{v})$ and subjected to fractionation with dichloromethane then by ethyl acetate to afford ethyl acetate fractions (18.5 and $9.2 \mathrm{gm}$ ) of $E p$ and $E g$, respectively.

\section{UPLC-ESI-MS/MS}

The sample $(100 \mu \mathrm{g} / \mathrm{ml})$ solution of each fraction (ethyl acetate fractions of E. p. and E.g.) were prepared using high performance liquid chromatography (HPLC) analytical grade solvent of $\mathrm{MeOH}$, filtered using a membrane disc filter $(0.2 \mu \mathrm{m})$ then subjected to LC-ESI-MS analysis. Samples injection volumes $(10 \mu \mathrm{l})$ were injected into the UPLC instrument equipped with reverse phase $\mathrm{C}-18$ column (ACQUITY UPLC-BEH C18 $1.7 \mu \mathrm{m}$ particle size- $2.1 \times 50 \mathrm{~mm}$ column). Mobile phase elution was made with the flow rate of $0.2 \mathrm{ml} / \mathrm{min}$ using gradient mobile phase comprising two eluents: eluent $\mathrm{A}$ is $\mathrm{H}_{2} \mathrm{O}$ acidified with 0.1 $\%$ formic acid and eluent $\mathrm{B}$ is $\mathrm{MeOH}$ acidified with $0.1 \%$ formic acid. Elution was performed using the following gradient: $20 \% \mathrm{~B}, 0-1 \mathrm{~min}$; $20-90 \% \mathrm{~B}, 1-18 \mathrm{~min} ; 20 \% \mathrm{~B}, 18-20 \mathrm{~min}$. Mass spectra were detected in the ESI negative ion mode between $\mathrm{m} / z$ 50-900 at $30 \mathrm{ev}$ capillary conc. and capillary voltage $3 \mathrm{KV}$. The peaks and spectra were processed using the Maslynx 4.1 software and tentatively identified by comparing its retention time $(R t)$ and mass spectrum with reported data. For fragmentation collision energy $40 \mathrm{eV}$ was used.

\section{Hepatoprotective materials}

\section{Animals}

Male Sprague Dawley rats weighting $(220 \pm 5 \mathrm{~g})$ and Balb C mice (20$25 \mathrm{~g}$ ) were purchased from Theodor Bilharz Institute (Giza, Egypt). The animals were housed in the animal facility of Faculty of Pharmacy (Boys), Al-Azhar University, Cairo, Egypt. They were fed with standard diet pellets (El-Nasr Company, Abou-Zaabal, Cairo, Egypt), and allowed free access to water. The animals were kept at room temperature $\left(25^{\circ} \mathrm{C} \pm 2.0\right)$ and natural humidity (it was 555$)$ with $12 \mathrm{~h}$-light/12 h dark cycle. The experiments were conducted in accordance with the ethical guidelines for investigations in laboratory animals and comply with the guidelines for the care and use of laboratory animals. The approval committee was given by ZU-IACUC committee with approval number ZU-IACUC/3/F/145/2019.

\section{Chemicals}

Silymarin (Sil): it was purchased as yellow fine powder and dissolved in normal saline, from Sigma-Aldrich Chemical Company, St. Louis, MO, USA. Thioacetamide (TAA): was purchased as powder purity (98.1 \%) then dissolved in normal saline, from Sigma-Aldrich Chemical Company, St. Louis, MO, USA.

\section{Acute toxicity or lethality $\left(\mathrm{LD}_{50}\right)$ test}

To assess for $E p$ and $E g$ extracts safety margin, the lethality test $\left(\mathrm{LD}_{50}\right)$ was carried out by estimation of acute toxicity monitored in animals. Ethyl acetate fractions of Ep and $E g$ were dissolved in dist. water at the mentioned doses below. The $\left(\mathrm{LD}_{50}\right)$ was estimated in mice by oral intake according to OECD guidelines No. 420. At a preliminary test, the mice were divided into three groups each of 12 animals and each animal received one dose of $5000 \mathrm{mg} / \mathrm{kg}$ body weight of the mice. Animals were kept under observation for $24 \mathrm{~h}$ for any signs of toxicity or cases of deaths. Control animals received the vehicle (normal saline) and were kept under the same conditions without any treatment. Toxicity signs and number of deaths for each extract during $24 \mathrm{~h}$ were recorded and the $\mathrm{LD}_{50}$ was calculated as the geometric mean of the dose. The results obtained showed no lethality.

\section{Antifibrotic effect}

Ethyl acetate fractions of $E p$ and $E g$ were dissolved in dist. water at the required doses, forty eight rats were divided into eight groups, six animals each, and the following schedule of treatment was adopted: Group
1 (Control group): rats were given normal saline daily $(2 \mathrm{ml} / \mathrm{kg}$ b.w., orally) for 4 consecutive weeks and served as negative control group. Group 2 (TAA): rats were injected intra-peritoneal with TAA (200 mg/ $\mathrm{kg}$ b.w.) dissolved in saline three times weekly for 4 consecutive weeks. Group 3 (Sil): rats were treated with silymarin orally (50 mg/kg b.w.) dissolved in normal saline daily for 4 consecutive weeks. Group $4(E p)$ : rats were administered $E p$ fraction orally ( $200 \mathrm{mg} / \mathrm{kg}$ b.w.) dissolved in normal saline daily for 4 consecutive weeks. Group 5 (Eg): rats were treated with $E g$ ethyl acetate fraction orally ( $200 \mathrm{mg} / \mathrm{kg}$ b.w.) dissolved in normal saline daily for 4 consecutive weeks. Group 6 (Sil+TAA): rats were pretreated orally with silymarin then with thioacetamide daily for 4 consecutive weeks. Group 7 (Ep+TAA): rats were pretreated orally with Ep ethyl acetate fraction then with thioacetamide daily for 4 consecutive weeks using the same dose schedules as mentioned above. Group 8 (Eg+TAA): rats were pretreated orally with $E g$ ethyl acetate fraction then with TAA for 4 consecutive weeks using the same dose schedules as mentioned above, plants fractions and silymarin were administered to the animals orally by gastric intubation for 4 weeks following the procedure of (Dutta et al., 2013) ${ }^{5}$.

\section{Serum and tissue preparations}

Samples of blood were collected retro-orbital venous plexus of rats (under light ether anesthesia) in non-heparinized tubes and for measuring biochemical parameters; the sera were separated. Later the animals were sacrificed; liver was dissected, washed in saline, blotted between dry filter papers and kept until antioxidants and histopathological examinations.

\section{Biochemical analysis}

Serum separated from blood samples was used for the determination of liver enzymes aspartate aminotransferase (AST), alanine aminotransferase (ALT), cholesterol (CH), triglycerides (TG), high density lipoprotein (HDL), low density lipoprotein (LDL) and total bilirubin $^{6}$. Part of liver tissue was homogenated and centrifuged at 5000 $\mathrm{rpm}$ for $10 \mathrm{~min}$ and the resulting supernatant was used for lipid peroxides malondialdehyde (MDA) contents, determination of oxidative enzymes; superoxide dismutase (SOD), catalase (CAT) activities, and reduced glutathione $(\mathrm{GSH})^{7,8}$. All tests were carried out using colorimetric spectrum Biodiagnostics ${ }^{\mathrm{TM}}$ and Diamond ${ }^{\mathrm{TM}}$ kits (Cairo, Egypt),

\section{Histopathological examination}

Autopsy samples were taken from the rats livers in the different groups and fixed in $10 \%$ neutral buffered formalin for $24 \mathrm{~h}$. Then serial dilutions of alcohol (ethyl, absolute ethyl and methyl) were used in specimens' dehydration. The specimens were cleaned by xylene and embedded in paraffin in a hot air oven at $56^{\circ} \mathrm{C}$ for $24 \mathrm{~h}$. Paraffin bees wax tissue blocks were prepared for sectioning at $4 \mu \mathrm{m}$ thicknesses by sledge microtone. The obtained sections of tissue were embedded between glass slides, deparaffinized, stained by hematoxylin and eosin stain, and another slides from the same samples stained with a specific stain (Masson $^{\otimes_{S}}$ trichrom) then all were examined using the light electric microscope ${ }^{9}$.

\section{Statistical analysis of data}

All data are presented as mean \pm SEM. Statistical analysis was performed using GraphPad prisim version 7 (GraphPad, San Diego, CA). Group differences were analyzed using one-way analysis of variance (ANOVA) followed by Tukey-Kramer for multiple comparison tests. The difference was considered significant at $P \leq 0.05$.

\section{RESULTS}

\section{UPLC-ESI-MS/MS identification of secondary metabolites}

Structural analysis of different compounds found in the aerial parts of Ep and Eg ethyl acetate fractions resulted in the separation and tentative 
identification of 32 compounds using ULPC-ESI-MS/MS. Identification of compounds was performed using $(\mathrm{M}-1)^{+} / \mathrm{MS}^{2}$ and comparison with reported data. Ellagitannins and phenolic acids (22.00 and 11.48 $\%)$, flavonoids such as quercetin glycosides (35.00 and $39.97 \%)$ and kaempferol glycosides (20.00 and $3.44 \%$ ) were found to be the major components in Ep and Eg, respectively; as ellagitannins (tetragalloyl hexoside, ellagic acid, gallic acid) and flavonoids (kaempferol-3-O$\beta$-(6"-galloyl-O-glucopyranoside, quercetin glycosides (glucoside and arabinoside) were found to be the major components in Ep while quercetin rutinoside and other quercetin glycosides (glucoside, arabinoside and rhamnoside) were highly abundant in $E g$. As observed; molecular and fragment ions were listed in Table 1. LC-MS/MS profiles for Ep and Eg ethyl acetate fractions in the negative ion mode are shown in (Figure 1).

\section{Identification of tannins}

Peak 1 with deprotonated molecular ion peak at $m / z 787$ [M-H] and $\mathrm{MS}^{2}$ at $m / z 635,483,331,169$, so it was tentatively identified as tetragalloyl hexoside ${ }^{10}$. While peak 2 was tentatively identified as gallic acid as its deprotonated molecular ion peak at $m / z 169[\mathrm{M}-\mathrm{H}]$ and $\mathrm{MS}^{2}$ at $m / z 125(\mathrm{M}-\mathrm{H}-\mathrm{COOH})^{10}$. Peak 5 with molecular ion peak at $m / z 183$ [M-H] while $\mathrm{MS}^{2}$ at $m / z 125$, so it was tentatively identified as methyl gallate ${ }^{10}$. Peak 24 showed a molecular ion peak $[\mathrm{M}-\mathrm{H}]$ at $m / z 301$, and $\mathrm{MS}^{2}$ fragmentations at $m / z 151,211$ so it was identified as ellagic acid ${ }^{11}$. Peaks 8 and 10 with deprotonated molecular ion peak at $m / z 635[\mathrm{M}-\mathrm{H}]$ and $\mathrm{MS}^{2}$ at 483 [M-H-galloyl- $\left.\mathrm{H}_{2} \mathrm{O}\right], 331$ (M-H-2 (galloyl - $\left.\mathrm{H}_{2} \mathrm{O}\right)$ ), $169\left(\mathrm{M}-\mathrm{H}-\right.$ hexoside-2 (galloyl- $\left.\mathrm{H}_{2} \mathrm{O}\right)$ ), so they were tentatively identified as trigalloyl hexoside and its isomer respectively ${ }^{11}$.

Table 1: Compounds identified in the ethyl acetate fractions of $E$. paralias and E. geniculata by using UPLC ESI-MS/MS in negative ionization mode.

\begin{tabular}{|c|c|c|c|c|c|c|c|}
\hline No & RT min & $(M-H) M / z$ & $\mathrm{MS}^{2} / \mathrm{MS}$ fragment ions & Expected compounds & Ep \% & Eg \% & Ref \\
\hline 1 & 0.8 & 787 & $635,483,331,183,168.9$ & Tetragalloyl-O-hexoside & 6 & 1.52 & 10 \\
\hline 2 & 1.5 & 169 & 125 & Gallic acid & 6 & 1.07 & 15 \\
\hline 3 & 3.5 & 585 & $271(100 \%)$ & Nargarin-galloyl-hexoside & + & - & 12 \\
\hline 4 & 4.4 & 463 & $301(100 \%)$ & Quercetin-3-O-glucoside & + & + & \\
\hline 5 & 5.2 & 183 & 151,125 & Methyl gallate & 6 & 2.6 & 10 \\
\hline 6 & 6.2 & 353 & 191,179 & Chlorogenic acid & + & 1.07 & 12 \\
\hline 7 & 6.3 & 615 & $463,301(100 \%), 152,125$ & Quercetin-galloyl-hexoside & + & - & 10 \\
\hline 8 & 6.5 & 635 & $465,331,169$ & Tri-galloyl-hexoside & + & 0.46 & 10 \\
\hline 9 & 6.9 & 635 & $635,431,285$ & Kaempferol-rhamn.-acetyl-glu isomer. & 2 & 1.44 & 16 \\
\hline 10 & 7.1 & 635 & 331,169 & Trigalloyl hexoside isomer & - & 1.75 & 10 \\
\hline 11 & 7.5 & 461 & 299 & Diosmetin hexoside & + & - & \\
\hline 12 & 7.7 & 433 & $301(100 \%)$ & Quercetin xyloside & + & - & \\
\hline 13 & 8.3 & 325 & 193 & Ferulic acid pentoside & - & + & \\
\hline 14 & 8.4 & 461 & 285 & Kaempferol-glucoronide & + & - & 15 \\
\hline 15 & 8.7 & 599 & $447,285,169$ & kaempferol-3-O- $\beta$-(6"-galloyl-0- glu) & 15 & + & \\
\hline 16 & 9.1 & 431 & $285(100 \%)$ & Kaempferol rhamnoside & + & - & \\
\hline 17 & 9.2 & 651 & $609,447,301(100 \%)$ & Quercetin-cetyl-hexoside- rhamnoside & - & + & 13 \\
\hline 18 & 9.34 & 927 & $927,463,301,151$ & Quercetin-3-O-glucopyranoside & 28 & 6.25 & 14 \\
\hline 19 & 9.8 & 433 & $433,301,151$ & Quercetin-3-O-arabinoside & 7 & 8.58 & 10 \\
\hline 20 & 9.9 & 615 & $463,301(100 \%)$ & querectin-galloyl glucopyranoside & - & + & 16 \\
\hline 21 & 10.0 & 609 & $301,447(100 \%)$ & Quercetin-rutinoside (rutin) & - & 8.74 & 10 \\
\hline 22 & 10.2 & 447 & $301,447,609$ & Quercetin-3-rhamnoside & - & 16.4 & 13 \\
\hline 23 & 10.4 & 447 & 447,285 & Kaempferol-3-O-glucopyranoside & 3 & + & 10 \\
\hline 24 & 11.8 & 301 & 211,151 & Ellagic acid & 4 & 2 & 11 \\
\hline 25 & 11.9 & 431 & 285,255 & Kaempferol rhamnoside & - & + & 10 \\
\hline 26 & 13.4 & 609 & $299(100 \%)$ & Diosmetin derivative & - & + & 13 \\
\hline 27 & 13.6 & 651 & $\begin{array}{c}547[\mathrm{M}-104], 427[\mathrm{M}-104-120] \\
301[\mathrm{M}-350]\end{array}$ & Quercetin-3-rhamnoside-acetyl hexoside & - & + & \\
\hline 28 & 18.4 & 635 & $285(100 \%), 227,241$ & Kaempferol-rhamnosyl-acetyl glucoside & - & + & 10 \\
\hline 29 & 23.7 & 301 & 151 & Quercetin & + & + & \\
\hline 30 & 23.4 & 285 & 151,125 & kaempferol & - & + & \\
\hline 31 & 12.8 & 329 & 269 & Dimethoxy apigenin & + & - & 13 \\
\hline 32 & 26.4 & 329 & $\begin{array}{c}314[\mathrm{M}-\mathrm{CH} 3], 299\left[\mathrm{M}-2 \mathrm{CH}_{3}\right] \\
271[\mathrm{M}-2 \mathrm{CH} 3-\mathrm{CO}]\end{array}$ & Diosmetin dimethyl ether & + & - & \\
\hline
\end{tabular}




\section{Identification of phenolic acids and their derivatives}

Peak 6 with deprotonated molecular ion peak at $m / z 353[\mathrm{M}-\mathrm{H}]$ and $\mathrm{MS}^{2}$ at $m / z 191$ (M-H-caffeoyl, 161) and 179 (M-H-quinic) so it was tentatively identified as chlorogenic acid ${ }^{12}$. Peak 13 with deprotonated molecular ion peak at $\mathrm{m} / z 325(\mathrm{M}-\mathrm{H})$, and $\mathrm{MS}^{2}$ at $\mathrm{m} / z 193(\mathrm{M}-\mathrm{H}-$ arabinose) so it was tentatively identified as ferulic acid pentoside ${ }^{10}$.

\section{Identification of flavonoid compounds}

Many flavonoid glycosides were identified in the ethyl acetate fractions of $E p$ and $E g$ where peak 3 detected at $m / z 585[\mathrm{M}-\mathrm{H}]$ with daughter ions at $m / z 271,100 \%$ so it was attributed to naringenin-galloylglucoside ${ }^{13}$. Peaks $4,7,12,17-22,28$ and 31 all identified as quercetin derivatives as they have quercetin moiety (301 amu) at all, they are different in types of sugar moieties according to the $\mathrm{m} / \mathrm{z}$ lost during fragmentation process as (-glucose or galactose, -162), (-rhamnose, -146), (-xylose or arabinose, -132) and (-acetyl glucose, -206) and some of which identified as galloyl glycoside due to lose of galloyl moiety $(-152)$ as shown in table (1)..$^{10,13,14}$ As the same were peaks 9, 14-16, 23, 25, 29 and 30 were identified as kaempferol derivatives due to presence of kaempferoyl moiety (285 amu); In addition to sugars moieties and galloyl moiety as shown in table (1)..$^{10,15,16}$ Peak 11 identified as diosmetin-hexoside to presence of molecular ion peak at $\mathrm{m} / \mathrm{z} 461,[\mathrm{M}-\mathrm{H}]$ and $\mathrm{MS}^{2}$ fragments at 299 amu corresponding to diosmetin moiety (M-H- 162$)^{13}$. Peak 32 identified as dimethoxy apigenin due to molecular ion peak at $329 \mathrm{~m} / \mathrm{z}$ and daughter ion at $269 \mathrm{amu}^{13}$.

\section{Hepatoprotective}

Thioacetamide is hepatotoxic agent known to induce acute or chronic liver disease (fibrosis and cirrhosis) in the experimental animal model ${ }^{17}$. In the present work, TAA is used as potent hepatotoxic agent in rats. A dose of $200 \mathrm{mg} / \mathrm{kg}$ ip TAA administration is reported to be the cause of hepatic toxicity. Its effect is due to increased oxidative stress ${ }^{18}$.

\section{Acute toxicity or lethality $\left(L D_{50}\right)$ test}

The results showed that the animals survived during the $24 \mathrm{~h}$ observation and no visible signs of toxicity were observed. According to Hodge and Sterner toxicity scale ${ }^{19}$, the $\mathrm{LD}_{50}$ values of the two fractions were in the practically non-toxic categories.

\section{Antifibrotic effects}

\section{Evaluation of liver biochemical parameters}

Exposure of animals with the hepatotoxic agent, TAA resulted in significant $(p \leq 0.05)$ increase in the liver enzymes (ALT and AST) and total bilirubin in serum, lipid profiles $(\mathrm{CH}, \mathrm{TG}$ and $\mathrm{LDL})$ and lipid peroxidation (MDA) while significant decrease in HDL, GSH,

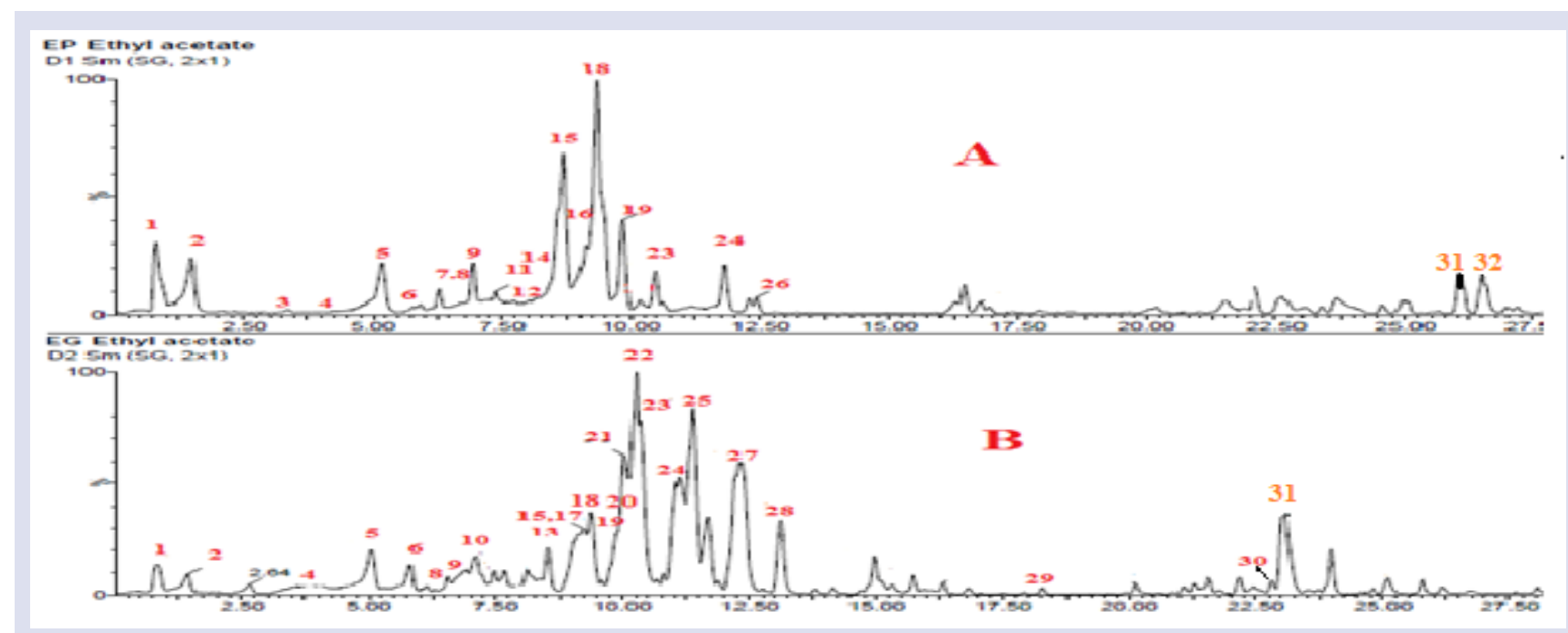

Figure 1: UPLC-ESI-MS/MS chromatogram of ethyl acetate fractions of E. paralias L. (A) and E. geniculata Ortega (B) in negative mode.
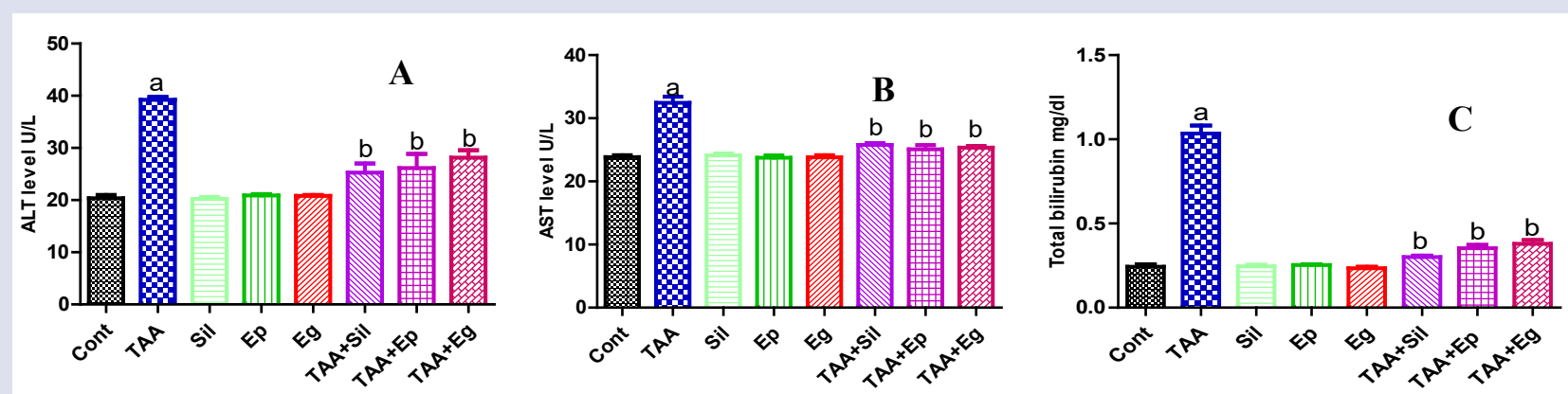

Figure 2: The effect of E. paralias, and E. geniculata on thioacetamide-treated rats in A: Alanine aminotransferase, B: Aspartate aminotransferase and C: Total bilirubin level on comparison with silymarin effect. 


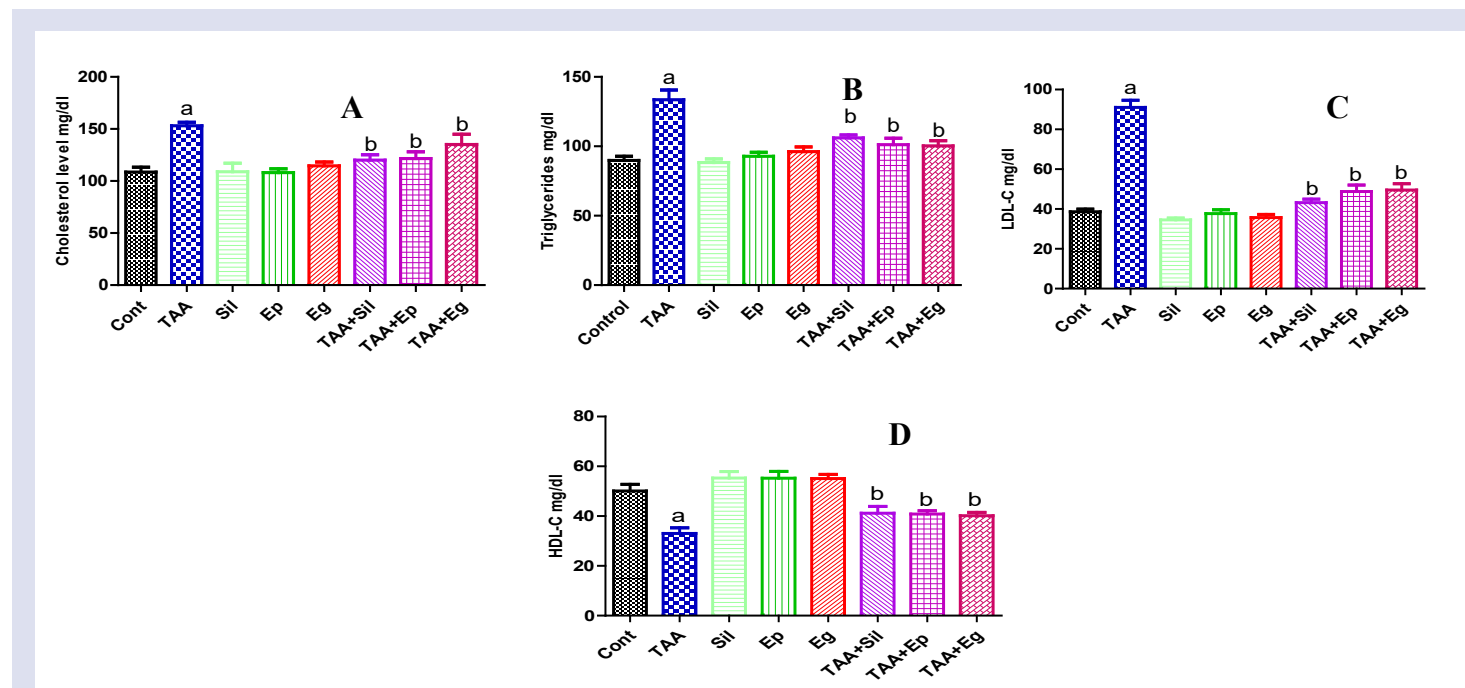

Figure 3: The effect of E. paralias, and E. geniculata on thioacetamid-treated rats on A: Cholesterol, B: triglycerides C: low density lipoprotein D: High density lipoprotein $\mathrm{mg} / \mathrm{dl}$ in thioacetamid-treated rats on comparison with Silymarin.

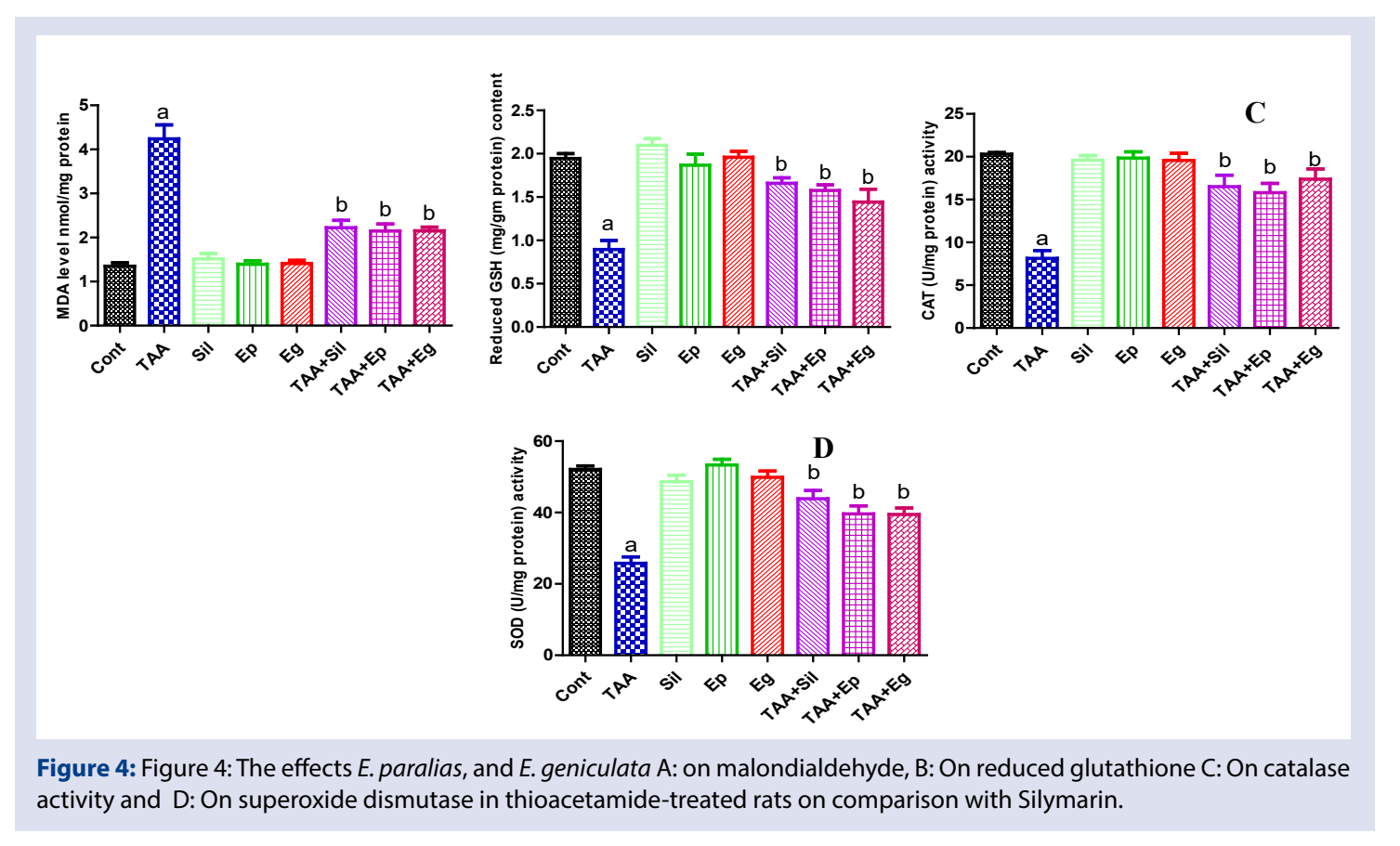

CAT and SOD), indicative of hepatocytes damage. ${ }^{8}$ Pretreatment of experimental animals with ( $E p$ and $E g$ ) EA fractions reversed the TAA-induced hepatotoxicity and restored the elevated levels of liver biomarkers toward normality in comparison with silymarin treated group as follow; Ep, Eg and silymarin caused significant decrease in the liver enzymes (ALT, AST and total bilirubin in serum) (Figure 2), lipid profiles (CH, TG and LDL) (Figure 3) and lipid peroxidation (MDA) while significant increase in HDL, GSH, CAT and SOD (Figure 4).

\section{Histopathological results}

Histopathological examinations of the sections of rat liver exposed to TAA showed (in $\mathrm{H}$ and $\mathrm{E}$ staining) severe tissue damage and hepatocytes degeneration. Ep and $E g$ pre-treatment attenuated the hepatic injury and showed significant protection of the hepatic cells from damage. There were no such alterations in Ep and Eg groups in compared to normal and silymarin treated groups (Figures 5 and 6).

\section{DISCUSSION}

The liver is the largest gland in the human body and susceptible to almost many different diseases including hepatitis, cirrhosis, alcohol related disorders and liver cancer. A major cause of these disorders is due to exposure to different environmental pollutants and xenobiotics ${ }^{20}$. Also, the exposure to a lot of chemicals, such as carbon tetrachloride, bromobenzene, ethanol, thioacetamide and polycyclic aromatic hydrocarbons have been implicated in the etiology of liver diseases ${ }^{21}$. It is fundamentally known that the regulation of apoptosis is a potential mechanism through which many agents such as polyphenolic compounds; can prevent toxicity and carcinogenesis ${ }^{22}$. Silymarin is a mixture of natural flavanolignans contains at least seven compounds ${ }^{23}$. The hepatoprotective and antioxidant activities of silymarin were attributed to control free radicals (FR), produced by the hepatic metabolism of toxic substances ${ }^{24}$. The present study revealed that both Ep and Eg contain several types of gallotannins, phenolic 


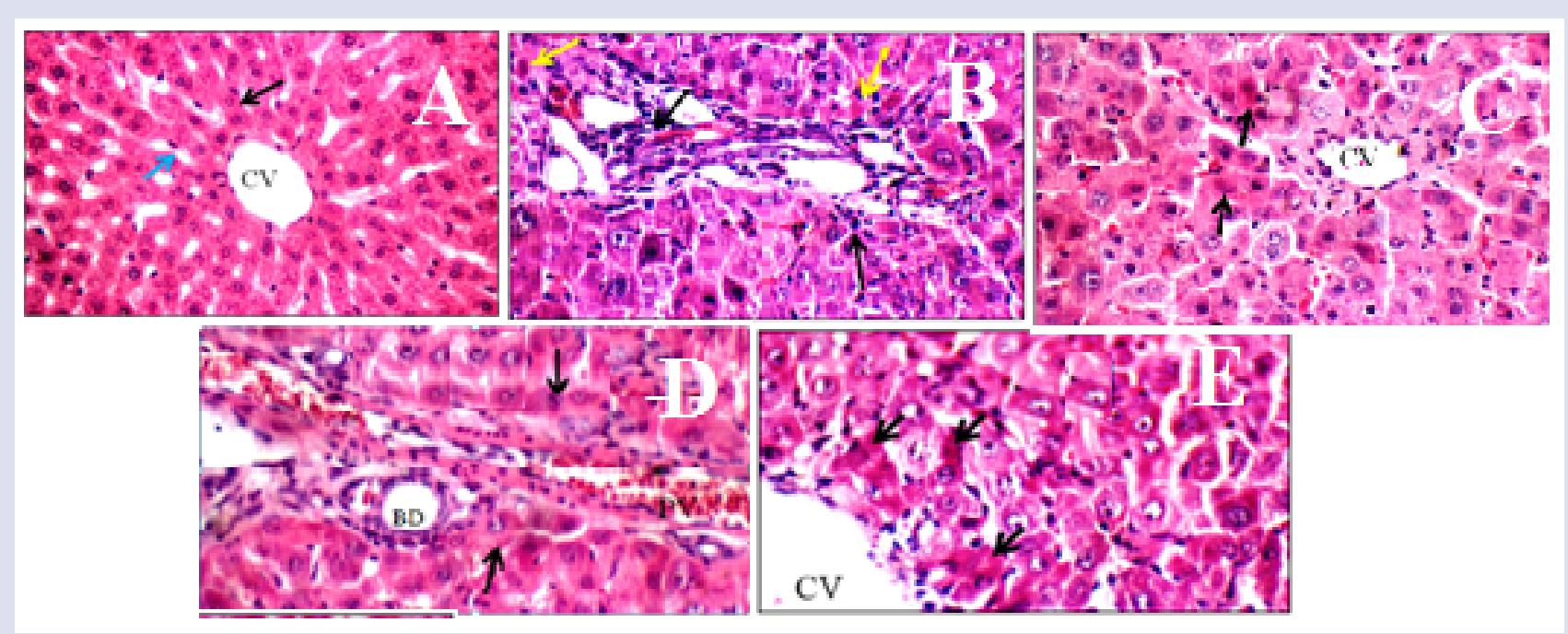

Figure 5: Light photomicrograph of $\mathrm{H} \& \mathrm{E}$ stain of liver sections tissues as A: (Cont gp): showing average central vein (CV), and hepatocytes arranged in single cell cords (black arrow) with intervening blood sinusoids. B: (TAA-gp): mildly expanded portal tract with mild portal and periportal inflammatory infiltrate (black arrows) and scattered apoptotic hepatocytes in peri-portal area (yellow arrow). C: (Sil+TAA gp): average central vein with apoptotic hepatocytes in peri-venular area (black arrows) D: (Ep+TAA gr): average portal tract with average portal vein (PV) and average hepatocytes in peri-portal area (black arrow) E: (Eg+TAA gp): dilated central veins, and scattered apoptotic hepatocytes in peri-venular area (black arrow) ( $\times 400$ except $\mathrm{D} \times 200)$.

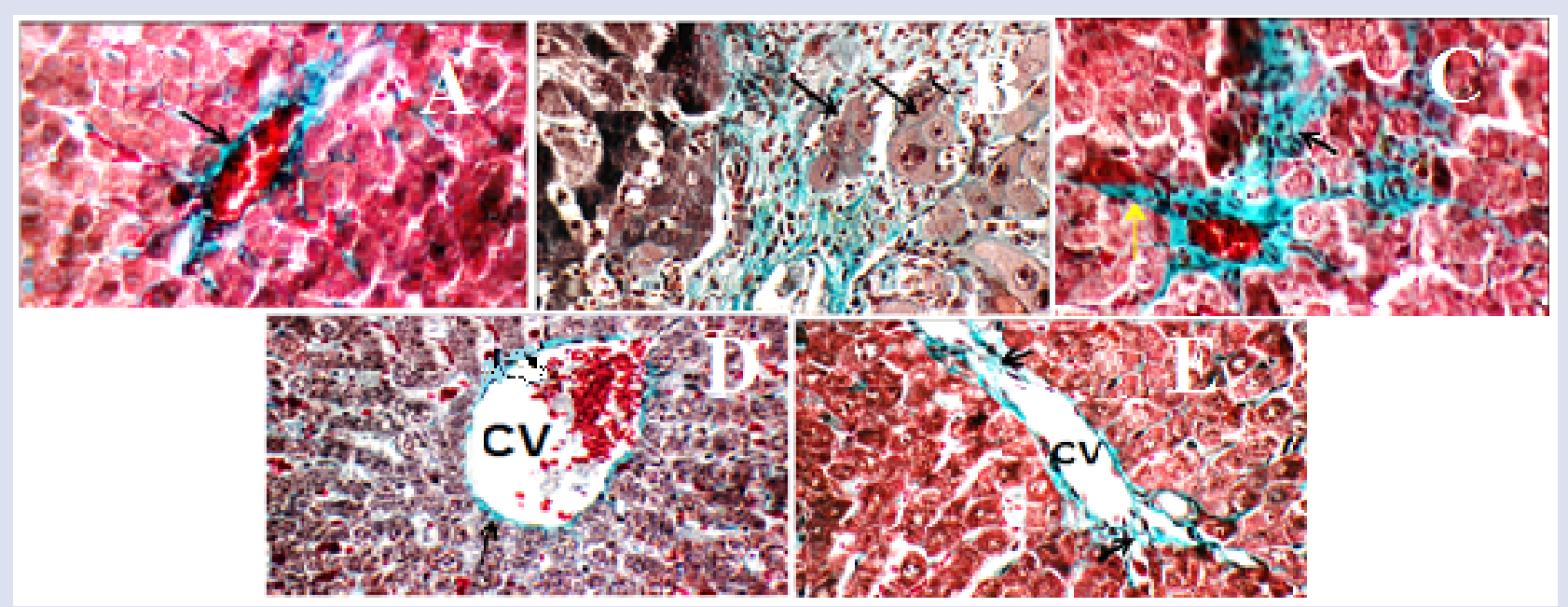

Figure 6: light photomicrograph Masson's trichrome as: A: (Cont gp): liver section showing average collagen distribution in portal tract (black arrows). B: (TAA gp): excess collagen bundles with complete nodule formation (black arrow). C: (Sil+TAA gp): high power view showing excess collagen in portal tracts with fibrous septa extending into hepatic lobule (yellow arrow). D: (Ep+TAA gp): average collagen around central vein (black arrow). E: (Eg+TAA gp): average collagen in portal tracts (black arrow) $(\times 400)$.

acids and flavonoids which tentatively identified through UPLC-ESIMS/MS analysis of ethyl acetate fractions of Ep and Eg. Polyphenolic compounds including flavonoids constitute 77.10 and $51.51 \%$ of the ethyl acetate fractions of $E p$ and $E g$, respectively. Quercetin and its derivatives in $E g(39.97 \%)$ represent about twice the kaempferol compounds in Ep (20.00\%). These compounds were known to have high antioxidant activity that attributed to their ability to control FR demonstrated by high hepatoprotective activity in comparison with standard drug silymarin ${ }^{25,26}$. That was evidenced by the significant improvement of liver enzymes (ALT and AST), total bilirubin, lipid peroxidation (MDA), oxidative stress related parameters (CAT, GSH and SOD) and lipid profile (CH, LDL, TG and HDL). According to the study; the potency strength of the fractions and silymarin on the liver enzymes differs from one to other; Ep+TAA gp show more improvement in ALT and $\mathrm{CH}$, than Eg+TAA gp but nearly equal to
Sil+TAA gp, while $E g+$ TAA gp show more improvement in GSH and CAT in comparison with Sil-gp but the both plant fractions were equally in improvement degree in the rest of liver enzymes. Histopathologicaly, parallel structural improvement was elicited by either plants extracts as compared to silymarin. This is evidenced by the views of rat's liver tissues treated with both plants as showing no collagen aggregation around central veins, no inflammatory infiltrate and no fibrosis. The results of the study on liver were indicating the promising values of these plants as hepatoprotective herbs in the future with more flow up.

\section{CONCLUSIONS}

This study revealed the identification of 32 polyphenolic compounds in the ethyl acetate fractions of the Ep and Eg using UPLC-ESI-MS/ MS analysis; mainly tannins and flavonoid glycosides. Hepatoprotective activity exhibited by the studied extracts might be attributed to the high 
content of these compounds. These findings need more explored and investigated through further set of experiments to recommend the ethyl acetate extracts of the two plants as hepatoprotective drugs of natural origin.

\section{ACKNOWLEDGEMENTS}

The authors would like to thank Dr. Ahmed Abdel Razik respective Lecturer of Plant Taxonomy, Department of Botany, Faculty of Science, Banha University, Banha, Egypt; for plants identification and supply.

\section{REFERENCES}

1. Dias DA, Urban $\mathrm{S}$, Roessner U. A historical overview of natural products in drug discovery. Metabolites 2012;2(2):303-36.

2. Van Wyk B-E, Wink M. Phytomedicines, herbal drugs and poisons. University of Chicago Press, Chicago; 2015

3. Van Wyk B-E, and Wink M., Medicinal plants of the world. $2^{\text {nd }}$ Ed, Pretoria: Briza; 2017.

4. Robin S, Sunil K, Rana AC, Nidhi S. Different models of hepatotoxicity and related liver diseases: a review. International Research Journal of Pharmacy. 2012;3:86-95.

5. Dutta B, Lahkar M, Bibin BA, Lihite M. Hepatoprotective activity of Tamarind indica and Homalomena aromatica in rats. International Journal of Pharmacy and Pharmaceutical Science. 2013;5(2):436-8.

6. Maheshwari N: Clinical Biochemistry. 1st Ed., Jaypee Brothers medical puplishers. Ltd., India; 2008.

7. Ramakrishman $\mathrm{S}$, Sulochana KN. Manual of medical laboratory techniques. 1st Ed., Jaypee Brothers Medical Puplishers Ltd., India; 2012.

8. Balahoroğlu R, Dülger H, Özbek, H, Bayram I, Şekeroğlu M. Protective effects of antioxidants on the experimental liver and kidney toxicity in mice. European Journal of General Medicine. 2008;5(3):157-64

9. Banchroft JD, Stevens A, Turner DR. Theory and practice of histological techniques, 4th ed. Churchill Livingstone, New York; 1996.

10. Abu-Reidah M I, Ali-Shtayeh S M, Jamous M R, Arráez-Román D, SeguraCarretero A. HPLC-DAD-ESI-MS/MS screening of bioactive components From Rhus coriaria L. (Sumac fruits). Food Chemistry. 2015;166:179-91.

11. Mena P, Calani L, Dall'Asta C, Galaverna G, García-Viguera C, Bruni R, et al. Rapid and Comprehensive Evaluation of (Poly)phenolic Compounds in Pomegranate (Punica granatum L.) Juice by UPLC-MSn. Molecules. 2012;17:14821-40.

12. Oszmiański J, Nowicka P, Teleszko M, Wojdyło A, Cebulak T, Oklejewicz K. Analysis of Phenolic Compounds and Antioxidant Activity in Wild Blackberry Fruits. Poland. International Journal Molecular Science. 2015;16(7):1454053.
13. Brito A, Ramirez JE, Areche C, Sepúlveda B, Simirgiotis MJ. HPLC-UV-MS Profiles of Phenolic Compounds and Antioxidant Activity of Fruits from Three Citrus Species Consumed in Northern Chile. Molecules Journal. 2014;19:17400-21.

14. Chen HJ, Inbaraj BS, Chen BH. Determination of Phenolic Acids and Flavonoids in Taraxacum formosanum Kitam by Liquid Chromatography-Tandem Mass Spectrometry Coupled with a Post-Column Derivatization Technique. International Journal Molecular Science. 2012;13:260-85.

15. Pisano B M, Cosentino S, Viale S, Spanò D, Corona A, Esposito F, et al. Biologica Activities of Aerial Parts Extracts of Euphorbia characias. Italy BioMed Research International. 2016;2016:11.

16. Sobeh M, El-Hawary E, Peixoto $H$, Labib RM, Handoussa $H$, Swilam N, et al. Identification of phenolic secondary metabolites from Schotia brachypetala Sond. (Fabaceae) and demonstration of their antioxidant activities in Caenorhabditis elegans. Peer Journal. 2016;2404.

17. Dwivedi DK, Jena GB. Glibenclamide protects against thioacetamideinduced hepatic damage in Wistar rat: investigation on NLRP3, MMP-2, and stellate cell activation. Naunyn-Schmiedeberg's. Archives of Pharmacology. 2018;391(11):1257-74.

18. Aftab A, Pillai KK, Shibli JA Balani DK, Najmi AK, Marwah R. Evaluation of the hepatoprotective potential of jigrine pre-treatment on thioacetamide induced liver damage in rats. Indian Journal of Pharmacology. 1999;3:416-21.

19. Sandu RB, Tarţău L, Miron A, Zagnat M, Ghiciuc CM, Lupuşoru CE. Experimenta researches on acute toxicity of a Bidens tripartita extract in mice-preliminary investigations. Revista Medico Chirurgicala a Societatii de Medici si Naturalist din Lasi. 2012;116(4):1230-4.

20. Sreelatha S, Padma P, Umadevi M. Protective effects of Coriandrum sativum extracts on carbon tetrachloride-induced hepatotoxicity in rats. Food and Chemical Toxicology. 2009;47(4):702-8.

21. Adesanoye OA, Farombi EO. Hepatoprotective effects of Vernonia amygdalina (Astereaceae) in rats treated with carbon tetrachloride. Experimental and Toxicologic Pathology. 2010;62(2):197-206.

22. Srivastava A, Akoh CC, Fischer J, Krewer G. Effect of anthocyanin fractions from selected cultivars of Georgia-grown blueberries on apoptosis and phase II enzymes. Journal of Agriculture and Food Chemistry. 2007;55(8):3180-5.

23. Morales-González JA Gayosso-Islas E Sánchez-Moreno C Valadez-Vega C Morales- González A, Esquivel-Soto J, et al. Protective effect of silymarin on liver damage by xenobiotics. In: Oxidative stress and chronic degenerative diseases-a role for antioxidants, editor. Rijeka: Croatia InTechOpen; 2013.

24. Flora K, Hahn M, Rosen H, Benner K. Milk thistle (Silybum marianum) for the therapy of liver disease. American Journal of Gastroenterol. 1998;93:139-43.

25. Afifi NA, Galal, MA, Ibrahim MK. Hepato-protective influence of quercetin and ellagic acid on thioacetamide-induced hepatotoxicity in rats. Canadian Journal of Physiology and Pharmacology. 2018;96(6):624-9.

26. Yanqing Z, Dongjie Z, Changqing Yu, Chenghao J, Kihru I. Antioxidant and hepatoprotective activity of Kaempferol-3-O-B-D-(2,6-di- $\alpha$-L-rhamnopyranosyl) galactopyranoside against carbon tetrachloride-induced liver injury in mice. Food Science Biotechnology. 2017;26(4):1071-6. 


\section{GRAPHICAL ABSTRACT}

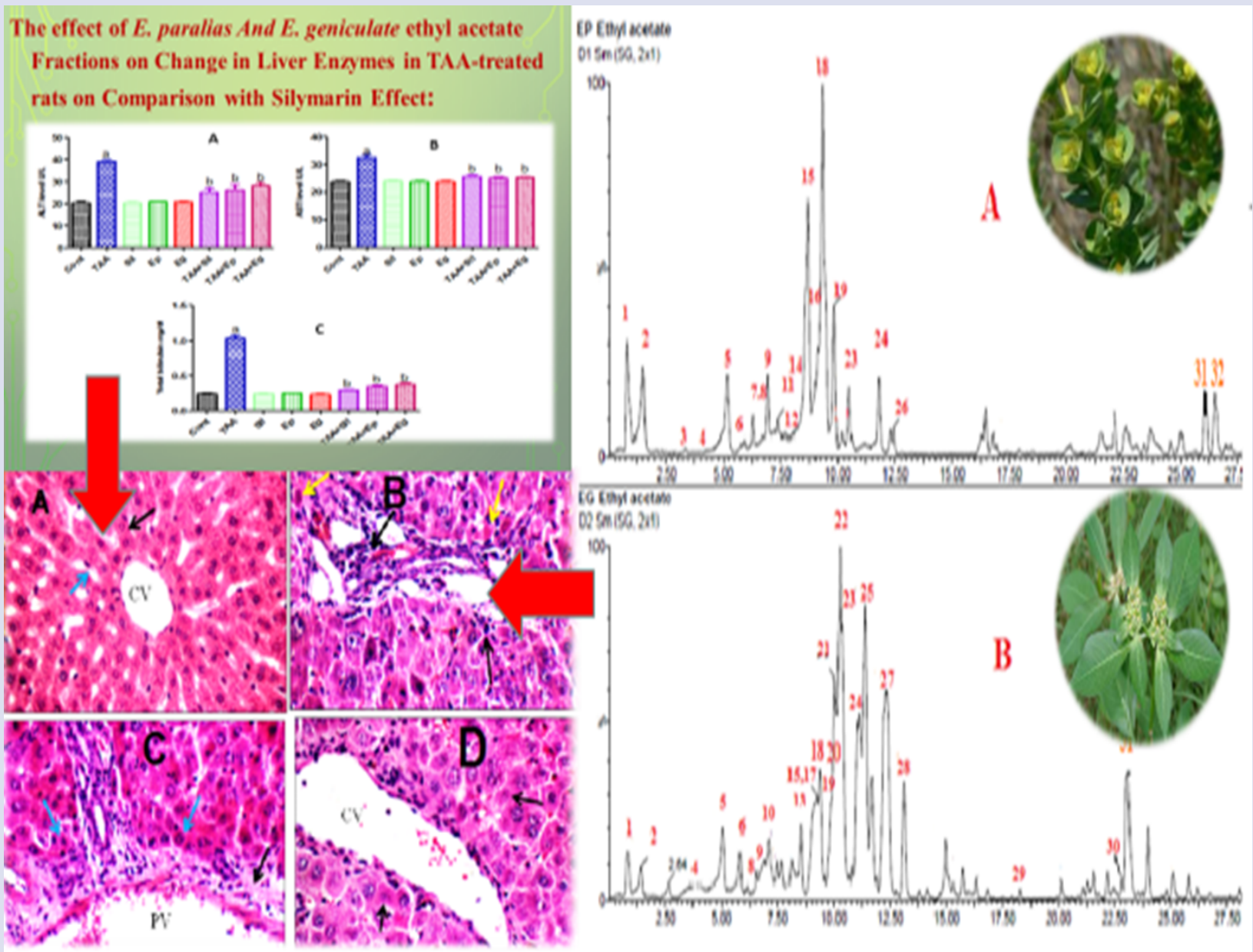

\section{ABOUT AUTHORS}

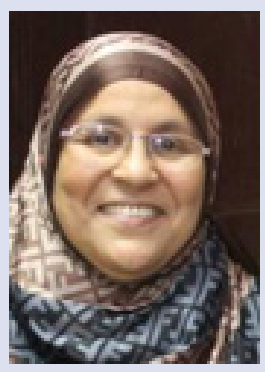

Prof. Dr. Afaf El-sayedAliAbdel Ghani graduated in pharmaceutical sciences in 1981 and subsequently completed her MSc (1985) at University of Zagazig and PhD (1990) degree in Doctorate of philosophy through a channel system mission with the institute of pharmaceutical chemistry, Bonn University, Germany. Assistant Prof. (1998) in Pharmacognosy, Faculty of Pharmacy, Zagazig University, Zagazig, Egypt. Professional in May 2005 as Prof. of pharmacognosy at Faculty of Pharmacy Zagazig University.

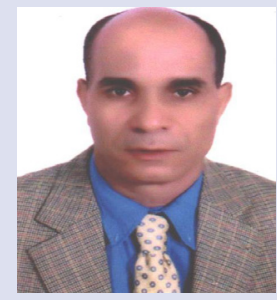

Prof. Dr. Sayed El-Toumy graduated in chemistry in 1984 and subsequently completed his MSc (1994) and PhD (1997) degrees in natural products at the Cairo University. He undertook post-doctoral at University of Leipzig, Institute of Pharmacy, Germany, (4-5-2002 to 26-4-2003). He was appointed as associate professor in 2005 and as full professor in 2011. His research interests are the isolation, identification and elucidation structure of polyphenolic compounds from folk medicinal plants using modern techniques and their application. 


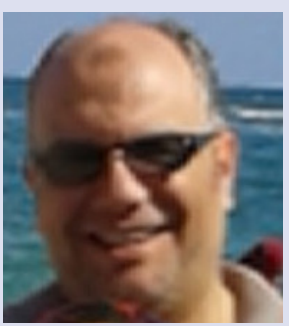

Prof. Dr. Wagdy Ibrahim Ahamed Ali El-Dougdoug Prof. Dr. Wagdy Ibrahim Ahamed Ali El-Dougdoug graduated in Special Chemistry in 1986 and subsequently completed his MSc in Organic Chemistry, Zagazig University (1991), and Ph.D. in Organic Chemistry, Zagazig University (1995). Assistant Professor in Organic Chemistry (2002) and professor in 2011. Head of Device of Organic Chemistry in 2015 until now in Chemistry Department, Faculty of Science, Banha University, Egypt. His position is Executive Director of Quality Assurance Faculty of Science, Banha, University (2013- Until now).

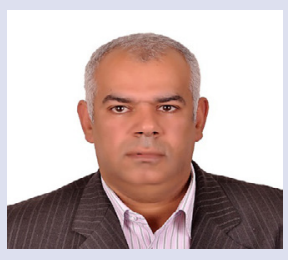

Prof. Dr. Ahmed Mohamed Ibrahim Mansour graduated in pharmaceutical sciences in 1991 and subsequently completed his MSc (1997) at Faculty of Pharmacy, El Azhar University and Ph.D. (2005) in Pharmacology, through channel system (Between Albert-Ludweege University, Freiburg, Germany and Pharmacology \& Toxicology Department, Faculty of Pharmacy, Al-Azhar University, Nasr City, Cairo, Egypt). Assistant Professor (2012) of Pharmacology \& Toxicology, Faculty of Pharmacy, Al-Azhar University. Professor of Pharmacology \& Toxicology (2017), Faculty of Pharmacy, Al-Azhar University, Nasr City, Cairo, Egypt.

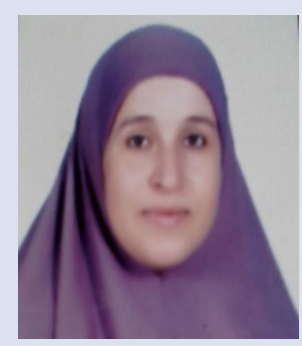

Prof. Dr. Wafaa Hassan Badr Hassan graduated in pharmaceutical sciences in 1989 and subsequently completed her MSc (1996) at University of Zagazig and PhD (2004) degree in Doctorate of philosophy in pharmacognosy through a full grant from Heinrich Heine University, Düsseldorf, Germany. Assistant Professor (2013) of pharmacognosy at Faculty of Pharmacy Zagazig University. Professional in 2019 as Prof. of pharmacognosy at Faculty of Pharmacy Zagazig University.

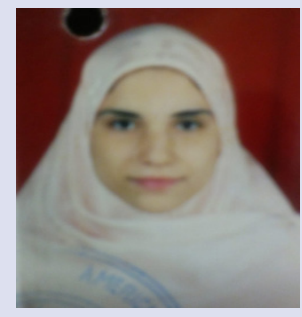

\section{Hanaa Mohamed zain El-Abdin Hassan}

Master Pharmacist on first degree in government Banha Hospital.

Bachelor of pharmacy Science: - 1996, Master degree in pharmaceutical sciences of pharmacognosy - 2012, from Zagazig, University, Zagazig, Egypt.

Cite this article: Ghani ASA, El-Toumy SA, El-Dougdoug WIA, Mansour AMI, Hassan WHB, Hassan HM. Chemical Profile and Hepatoprotective Activity of Ethyl Acetate Extracts of land Euphorbia geniculata (Euphorbiaceae) from Egypt. Pharmacogn J. 2020;12(4):762-70. 